\title{
Appendix figures
}

\section{Fully automated two-dimensional electrophoresis}

system for high-throughput protein analysis

\author{
Atsunori Hiratsuka, ${ }^{1}$ Hideki Kinoshita, ${ }^{1}$ Yuji Maruo, ${ }^{2}$ Katsuyoshi Takahashi, ${ }^{2}$ Satonari Akutsu, ${ }^{3,5}$ Chie \\ Hayashida, ${ }^{3}$ Koji Sakairi, ${ }^{3}$ Keisuke Usui, ${ }^{1}$ Kisho Shiseki, ${ }^{1}$ Hajime Inamochi, ${ }^{4}$ Yoshiko Nakada, ${ }^{4}$ Kouhei \\ Yodoya, ${ }^{4}$ Ichiji Namatame, ${ }^{4}$ Yutaka Unuma, ${ }^{2}$ Makoto Nakamura, ${ }^{2}$ Kosuke Ueyama, ${ }^{3}$ Yoshinori Ishii, ${ }^{4}$ \\ Kazuyoshi Yano, ${ }^{5}$ Kenji Yokoyama ${ }^{1 *}$
}

${ }^{1}$ Research Center of Advanced Bionics, National Institute of Advanced Industrial Science and Technology (AIST)

${ }^{2}$ Biosensing Systems Laboratories, Sharp Corp.

${ }^{3}$ Product Innovation Laboratory, Technical Research Institute, Toppan Printing Co., Ltd.

${ }^{4}$ Astellas Pharma Inc.

${ }^{5}$ Faculty of Bionics, Tokyo University of Technology

*Corresponding author (ke-yokoyama@aist.go.jp) 


\section{Appendix figure 1}

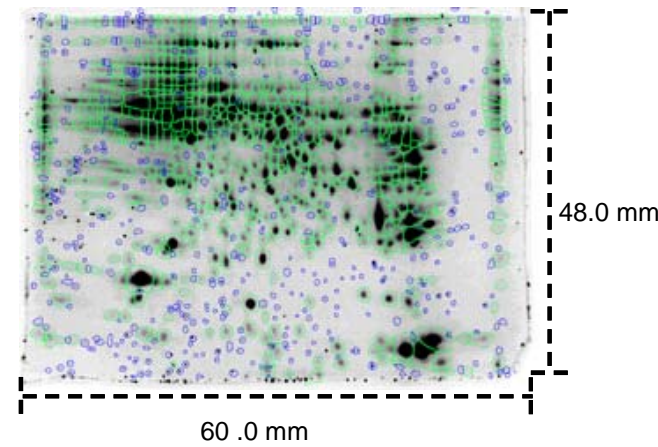

a

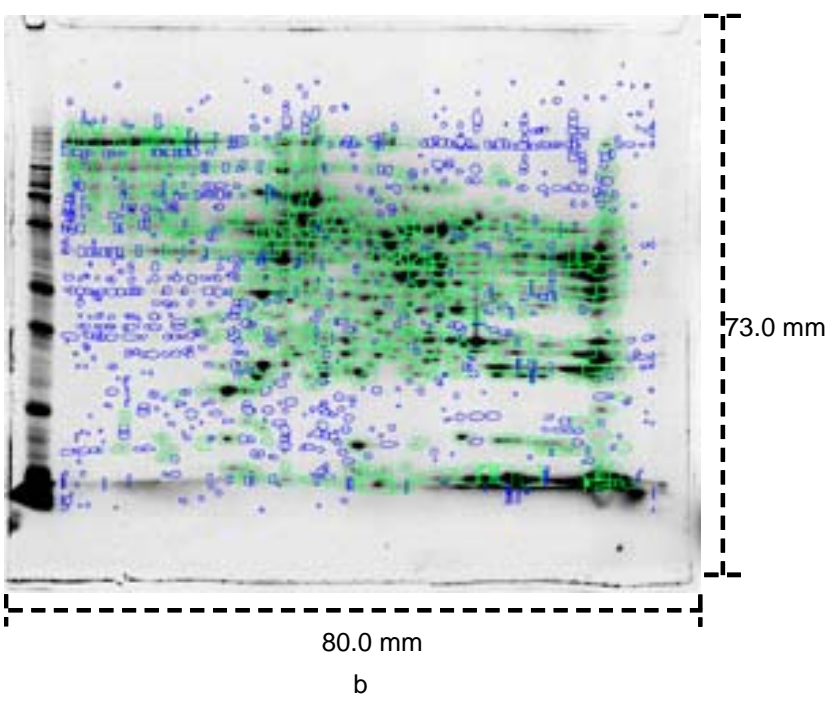

2D Image analysis of spot numbers

a: Automated system, b: Commercial mini-gel system (Bio-Rad Laboratories)

Column (Green and Blue): detected spots by the Image analysis software, Blue column: rejected spots by manual operations,

Green column: remained spots for number calculations 
Appendix figure 2

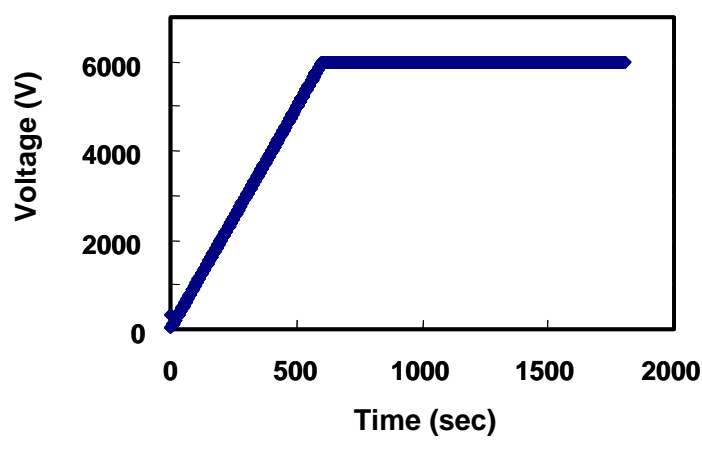

a

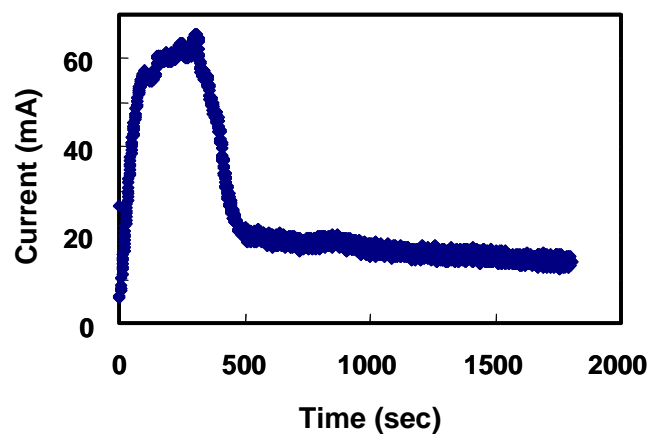

b

Voltage and current variation during IEF operation using the automated system

(a): Voltage v.s. time graph, (b) Current v.s. time graph 


\section{Appendix figure 3}

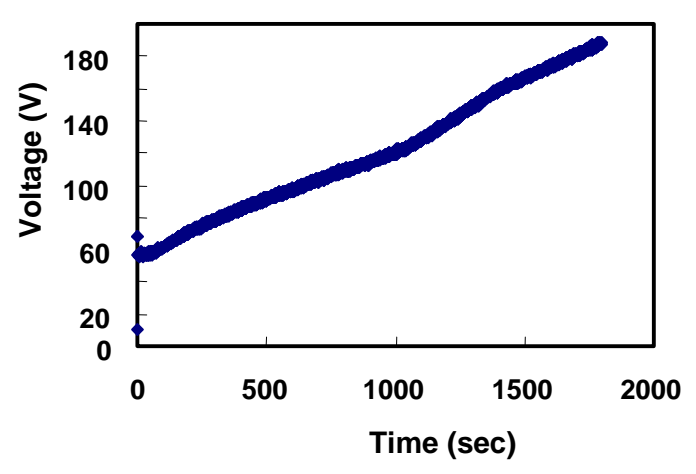

a

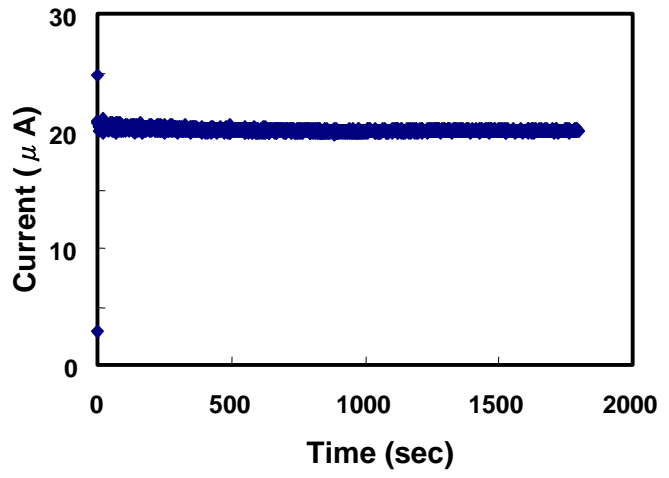

b

Voltage and current variation during SDS-PAGE operation using the automated system (a): Voltage v.s. time graph, (b) Current v.s. time graph 